\title{
8
}

\section{im

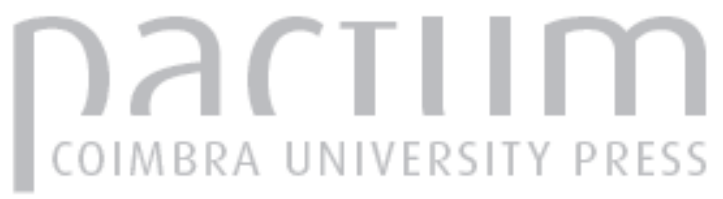

\section{O ilustre humanista Fernão Lopes Milão e as tentativas de fuga da sua família para Hamburgo}

\author{
Autor(es): $\quad$ Frade, Florbela Veiga
}

Publicado por: Centro de História da Sociedade e da Cultura

URL persistente:

URI:http://hdl.handle.net/10316.2/39518

DOI:

DOI:http://dx.doi.org/10.14195/1645-2259_10-1_8

Accessed : $\quad$ 26-Apr-2023 06:18:55

A navegação consulta e descarregamento dos títulos inseridos nas Bibliotecas Digitais UC Digitalis, UC Pombalina e UC Impactum, pressupõem a aceitação plena e sem reservas dos Termos e Condições de Uso destas Bibliotecas Digitais, disponíveis em https://digitalis.uc.pt/pt-pt/termos.

Conforme exposto nos referidos Termos e Condições de Uso, o descarregamento de títulos de acesso restrito requer uma licença válida de autorização devendo o utilizador aceder ao(s) documento(s) a partir de um endereço de IP da instituição detentora da supramencionada licença.

Ao utilizador é apenas permitido o descarregamento para uso pessoal, pelo que o emprego do(s) título(s) descarregado(s) para outro fim, designadamente comercial, carece de autorização do respetivo autor ou editor da obra.

Na medida em que todas as obras da UC Digitalis se encontram protegidas pelo Código do Direito de Autor e Direitos Conexos e demais legislação aplicável, toda a cópia, parcial ou total, deste documento, nos casos em que é legalmente admitida, deverá conter ou fazer-se acompanhar por este aviso.

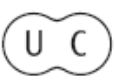




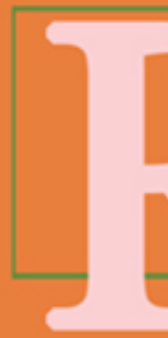

\section{evista de História}

da Sociedade e da

Cultura

\section{Tomo I}

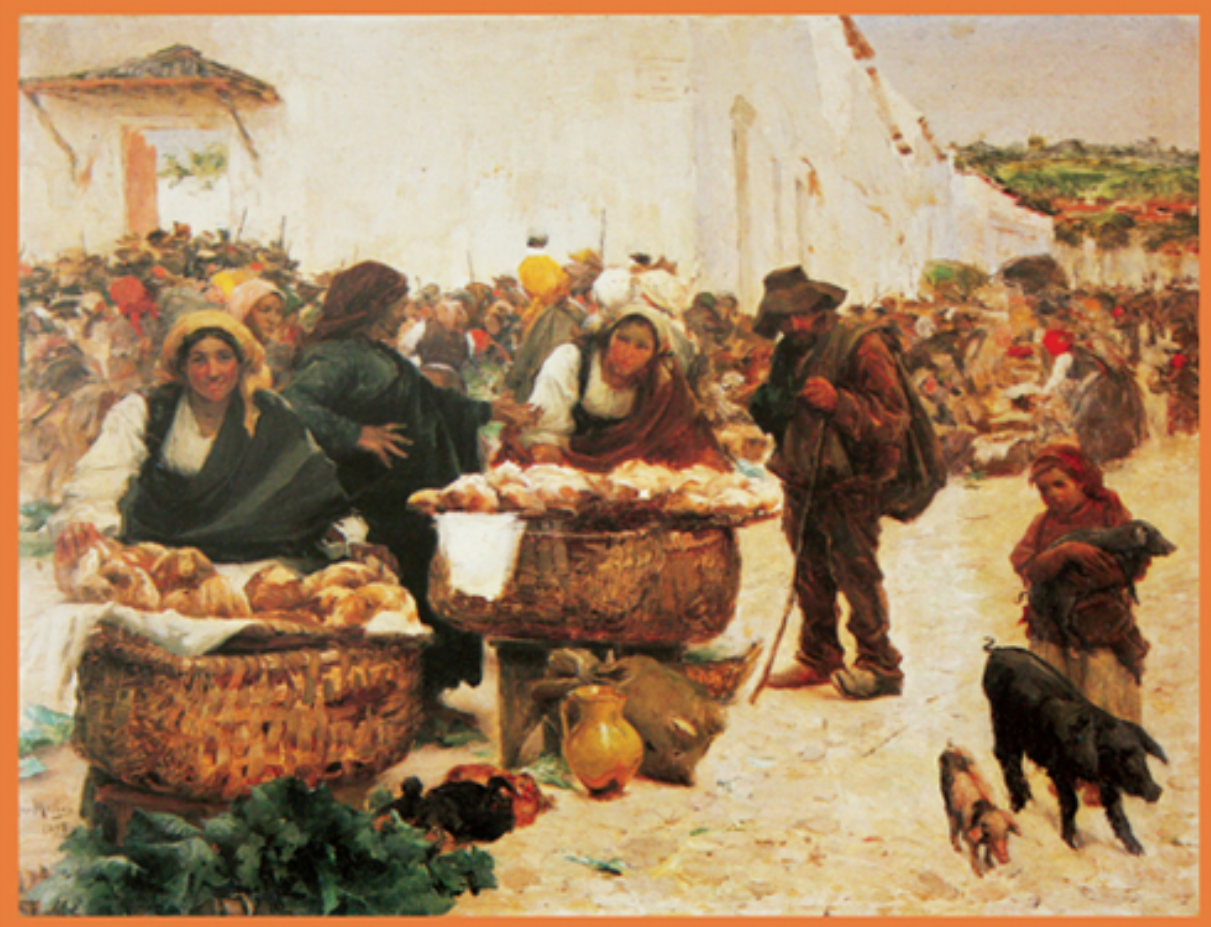

Centro de História da Sociedade e da Cultura Universidade de Coimbra

Coimbra 


\title{
O ilustre humanista Fernão Lopes Milão e as tentativas de fuga da sua família para Hamburgo
}

\author{
Florbela Veiga Frade \\ Bolseira da Fundação para a Ciência e Tecnologia \\ Investigadora da Faculdade de Letras da Universidade do Porto \\ Institut für die Geschichte der Deutschen Juden \\ fveigafrade@netcabo.pt \\ Texto recebido em/ Text submitted on: 28/02/2010 \\ Texto aprovado em/ Text approved on: 23/04/2010
}

\section{Resumo/Abstract:}

Os Milão eram uma família de ricos cristãos-novos que arrematavam os contratos régios contribuindo de forma destacada para a economia portuguesa. Fernão Lopes Milão era um poliglota que escrevia sem parar, mesmo nos cárceres da Inquisição. No seu espólio contavam-se tratados sobre o bom governo, Matemática aplicada à Sagrada Escritura. Sabia a cronologia antiga, as medidas do Templo de Salomão e da Arca da Aliança. Este humanista português foi aluno de Lavanha e do padre Manuel Correia, um latinista e hebraista amigo de Luís de Camões. Foi correspondente de Lorenzo Ramirez de Prado, Martin de los Rios e Justo Lipsio a propósito da tradução para português dos Anales de Tácito. A passagem pelos cárceres da Inquisição apagou da memória colectiva a produção literária de Lopes Milão, contudo o legado do Santo Ofício está hoje disponível sendo possível através dele reconstituir uma parcela da realidade literária e cultural do Renascimento Português.

The wealthy New Christian family Milão gained several royal contracts, providing for many decades significant input to the Portuguese economy. Fernão Lopes Milão was a polyglot that wrote, even under prison, several treaties on the topics of good governance and mathematics applied to the Holy Scriptures. He knew exact dates, the measurements of the Temple of Solomon and of the Ark of the Covenant. This Portuguese humanist was a pupil of Lavanha and of Father Manuel Correia, a Latinist and Hebraist friend of Luís de Camões. He corresponded with Lorenzo Ramirez de Prado, Martin de los Rios and Justus Lipsius on the translation to Portuguese of Tacitus's Annales. His confinement under the Inquisition wiped from the collective memory all of Milão's literary works. However, currently the Holy Office archive is public, which permits the reconstruction of part of the literary and cultural reality during Portuguese Renaissance.

Palavras chave/Keywords:

Cristãos-Novos; Livraria; Mercador; Inquisição; Tácito.

New Christians; Private library; Merchant; Inquisition; Tacitus. 


\section{Fernão Lopes Milão, a sua formação e círculo de amigos}

Fernão Lopes Milão nasceu ${ }^{1}$ por volta do ano de 1575 em Lisboa no seio duma família cristã-nova de vastos recursos encabeçada por Henrique Dias Milão, um contratador de renome internacional. Foi baptizado na igreja de S. Nicolau, apadrinhado por D. Fernando de Meneses e Guiomar de Solis². Ao contrário dos seus irmãos, Fernão Lopes deu preferência ao estudo embora não descurasse os seus afazeres de mercador. A sua curiosidade advinha-lhe também dos estudos no Colégio de Santo Antão em Lisboa onde aprendeu Gramática, ouviu os princípios de Filosofia e estudou Matemática.

De acordo como o seu processo inquisitorial estudou Matemática durante três anos interpolados, tendo como mestres os padres da Companhia no Colégio de Santo Antão e João Baptista Lavanha³. No Colégio, o curso de Matemática só se iniciou por volta de 1590 coincidindo com a passagem da primeira para a segunda sede 4 . Os professores desta disciplina eram os arquitectos João Delgado ${ }^{5}$ e Francisco da Costa a quem sucedeu em 1599, na Aula da Esfera, Christoph Grienberger, retomando o ensino os antigos professores 6 .

Precisamente em 1591 João Baptista Lavanha ${ }^{7}$ foi nomeado cosmógrafo-mor de Portugal com obrigatoriedade de ensinar a cátedra de Matemática

1 Em Novembro de 1606 disse ter 31 anos cf. Instituto Arquivos Nacionais/Torre do Tombo, Inquisição de Lisboa, proc. 2523, fl. 132.

2 IANTT, Inquisição de Lisboa, proc. 2523, fl. 134.

3 IANTT, $I L$, proc. 2523, fl. 161-161v.

4 LEITÃO, Henrique - A Ciência na "Aula da Esfera” no Colégio de Santo Antão, 1590-1759. Lisboa: Comissariado Comemorações do V Centenário do Nascimento de S. Francisco Xavier, 2007, p. 27, 37. O Colégio de Santo Antão-o-Novo, inaugurado em 1593, acolhe actualmente o Hospital de S. José. No ano de 1591 o número de alunos teve um aumento fora do comum chegando aos 2.500. Decaiu para 1.800 em 1598. No século XVII os alunos rondavam os 2.000 sendo a mais importante instituição de ensino em Lisboa.

5 João Delgado também ensinava astrologia prática ou judiciária. Na Livraria dos Teatinos existia um manuscrito intitulado Astrologia Prática ou Judiciária ditado pelo dito padre de Santo Antão datado de 1607 com quatro tratados. Cf. Biblioteca Nacional de Portugal, COD 624, fl. 62.

${ }^{6}$ LEITÃO, Henrique - A Ciência, cit, p. 48-49. Grienberger liderou a Academia de Matemática do Colégio Romano. Sobre a aula da esfera v. ALBUQUERQUE, Luís de Estudos de História, vol. II. Coimbra: Atlântida, 1974, p. 127-200.

7 Sobre Lavanha ver MOTA, A. Teixeira da - Os Regimentos do Cosmógrafo-Mor de 1559 e 1592 e as Origens do Ensino Náutico em Portugal. Lisboa: Junta Investigação do 
devendo ainda examinar cartas e instrumentos de marear ${ }^{8}$. De acordo com o Regimento de 1592 o ensino de Matemática destinava-se a gente de mar e a gente nobre ${ }^{9}$ sendo lida por Lavanha numa casa ordenada para isso onde deveria ter os instrumentos necessários.

A avaliar pelos dois alvarás de nomeação para o ofício de cosmógrafo-mor de António de Mariz Carneiro, um sucessor de Lavanha, o ensino de Matemática deveria ter lugar na sua casa e se tivesse algum impedimento, o seu substituto ensinaria nos Armazéns ${ }^{10}$. Por conseguinte, não deverá estar muito longe da verdade afirmar-se que Fernão Lopes de Milão, a ter tido lições de Matemática com Lavanha, tivesse estudado em casa do cosmógrafo ou nos Armazéns da Casa da Índia no Terreiro do Paço em Lisboa.

Fernão Lopes Milão teria cerca de 16 anos em 1591, altura ideal para iniciar os estudos de Matemática no Colégio de Santo Antão ou com o cosmógrafo-mor que esteve em Lisboa até 1599 aproximadamente. Contudo, existe também a possibilidade de ter tido aulas particulares em Lisboa no mesmo período ou até em Madrid, com idade mais precoce, entre 1582 e 1591, onde poderia ter frequentado a Academia.

Voltemos ao que se sabe sobre a formação erudita de Fernão Lopes Milão, designadamente ao seu inusual interesse pelas línguas. Um mercador de finais do século XVI e inícios do XVII que ouviu grego e princípios de

Ultramar, 1969; DOMINGUES, Francisco - João Baptista Lavanha. Dicionário de História dos Descobrimentos Portugueses, vol. II. Lisboa: Círculo de Leitores, 1994, p. 586-588; id. - Os Navios do Mar Oceano. Lisboa: Centro de História, 2004, p. 109-157; POLÓNIA, Amélia - Mestres e Pilotos das Carreiras Ultramarinas. Revista da Faculdade de Letras. Historia, Porto, 1995, p. 276-277. Agradeço a Francisco Domingues, António Canas e Carina Esteves as indicações sobre Lavanha.

8 MOTA, A. Teixeira da-Os regimentos..., cit., p. 20-21; VITERBO, Sousa-Trabalhos Náuticos dos Portugueses. Lisboa: INCM, 1988, p. 176-177; POLÓNIA, Amélia-Mestres e Pilotos, cit., p. 276. João Baptista Lavanha, cristão-novo de Lisboa, serviu Filipe II, III e IV. Foi leitor na Academia de Matemática de Madrid com Pedro de Ondériz, contando-se - o que não é pacífico - entre os seus discípulos Cervantes e Lope de Vega. Em 1586, foi nomeado engenheiro do Reino de Portugal. Cf. DOMINGUES, Francisco - João Baptista Lavanha, cit., p. 586-588.

9 Regimento do Cosmógrafo-Mor, cap. 11 cf. MOTA, A. Teixeira da-Os Regimentos, cit., p. 32. Por gente de mar entendia-se pilotos, sota-pilotos, mestres e contramestres a quem estava confiado o governo dos navios. A gente nobre deveria escutar Matemática como forma de se habilitar para o serviço nas armadas. O regimento é omisso em relação aos mercadores.

${ }^{10}$ MOTA, A. Teixeira da - Os Regimentos, cit., p. 34. 
hebraico com Manuel Correia, cura de S. Sebastião na Mouraria ${ }^{11}$, não é muito comum e torna-se excepcional quando para além disso sabia latim, castelhano, italiano e lia francês ${ }^{12}$. A língua castelhana, a italiana e a francesa eram necessárias a quem tinha relações comerciais regulares com estas partes, como parece ser o caso da casa ou firma Milão.

No entanto, o latim, o grego e o hebraico ${ }^{13}$ não se coadunam com as conveniências pessoais e familiares ligadas ao tipo de comércio que praticava. $\mathrm{O}$ estudo daquelas línguas clássicas prefigura interesses intelectuais e teológicos que extravasam a mera comunicação com outras gentes. Implícito na escolha de Fernão Lopes Milão está o estudo de obras que circulavam pela Europa e pelo mundo de cariz político e geográfico, tão ao gosto da época e também aos mais recentes estudos e trabalhos dos humanistas europeus. Mas, acima de tudo, revela a possibilidade que teria em poder escrever e publicar para um público mais vasto, não menosprezando ainda a sua capacidade em poder estudar obras na sua língua original. Insere-se neste último aspecto a leitura do Pentateuco, não em aramaico mas em hebraico, assim como as obras dos autores clássicos e as dos sábios da Igreja.

Manuel Correia foi o ilustre mestre de Fernão Lopes da língua hebraica e grega e talvez mesmo de latim. Este pároco da igreja de S. Sebastião era licenciado em Cânones e examinador sinodal do arcebispado de Lisboa. Correspondia-se com Justo Lipsio, pois uma missiva sua encontra-se registada e transcrita em Centúria ${ }^{14}$, e foi amigo de Luís de Camões, publicando após a morte deste, em 1613 na casa de Pedro Craesbeeck, uns comentários aos Lusíadas intitulados Os Lusíadas do grande Luís de Camões, príncipe da poesia heróica dedicados ao Dr. D. Rodrigo da Cunha inquisidor apostólico. Para além disso escreveu uns poemas em louvor de Ambrósio Nunes na sua obra Aforismos de que existiria um exemplar na

${ }^{11}$ IANTT, $I L$, proc. 2523 , fl. 161-161v.

${ }^{12}$ IANTT, $I L$, proc. 2523 , fl. 166.

${ }^{13}$ Sobre o estudo do hebraico em Portugal e gramáticas ver RODRIGUES, Manuel Augusto - O Estudo do Hebraico em Portugal no Século XVI. Coimbra: Coimbra Ed., 1973; AMZALAK, Moses Bensabat - Portuguese Hebrew Grammars and Grammarians. Lisboa: s.n., 1928. Sobre o papel do latim e grego na divulgação de conhecimentos ver BURKE, Peter, ed. - Cultural Translation in Early Modern Europe. Cambridge: University Press, 2007.

${ }^{14}$ LIPSIO, Justo - Selectarvm Centvria Singvlaris ad Ítalos \& Hispanus. Antuérpia: Joannem Moretum, 1601, p. 124-125. 
Biblioteca da Ajuda. De acordo com Barbosa de Machado, o elvense Manuel Correia também dedicou uns poemas a Duarte Lobo na Arte da Música; contudo Inocêncio da Silva não encontrou nenhuma obra com este nome ou semelhante. O dito religioso e canonista deixou manuscritas duas obras, designadamente os Princípios de Gramática cujo original se encontraria na livraria dos Padres Teatinos; e a obra de Cornélio Tácito traduzida para português em quatro volumes ${ }^{15}$.

É precisamente esta obra de Tácito referida por Barbosa de Machado traduzida para português por Manuel Correia em quatro volumes que aguça a nossa curiosidade. Não se encontra referência a tal obra em parte alguma, mesmo na livraria dos Teatinos onde terá ficado o outro manuscrito de Manuel Correia. Para além disso, Fernão Lopes Milão, o discípulo erudito do referido padre, também se correspondeu com Justo Lipsio precisamente por causa da tradução dum excerto de Annales III, 68, 2, de Tácito ${ }^{16}$, onde tratava da herança de Silano, manifestando simultaneamente a intenção de verter para português aquela obra. Resta-nos questionar se a tradução de Tácito de autoria de Manuel Correia era resultado da sua dedicação e da de Fernão Lopes Milão ou se por volta da mesma altura mestre e discípulo escreveram duas versões diversas.

Neste último caso, apenas se pode constatar que a tradução manuscrita ou impressa de Tácito por Fernão Lopes Milão - onde deveria constar o excerto com os comentários relativos à herança por via feminina de Silano ${ }^{17}$ - se encontra desaparecida. O manuscrito da tradução deve ter existido, uma vez que Lorenzo Ramirez de Prado, numa carta de Novembro de 1604, instiga o seu amigo a entregá-lo aos impressores dizendo-lhe para acolher a fama

${ }^{15}$ MACHADO, Diogo Barbosa - Bibliotheca Lusitana, vol 3. Lisboa: Of. Ignacio Rodrigues, 1752, p. 232-233; SILVA, Inocêncio Francisco da-Diccionario Bibliographico Portuguez, vol. V, t. XVI. Lisboa: Imprensa Nacional, 1860, p. 403; idem, vol. V, tomo V, p. 158. Embora Barbosa de Machado localize os Princípios de Gramática na Livraria dos Teatinos, não nos foi possível encontrar nos diversos catálogos e índices disponíveis desta biblioteca, nomeadamente: Biblioteca Nacional de Portugal, COD 7407, COD 12935-37; COD 624; COD 7429-30.

${ }^{16}$ SOLIS DE LOS SANTOS, José - Dos cartas desconocidas de Justo Lipsio y outras seis que le ataquen en la correspondencia de Lorenzo Ramirez de Prado (1583-1658). Humanistica Lovaniensia. Journal of Neo-Latin Studies, $\mathrm{n}^{\circ}$ 47, Lovaina: Katholieke Universiteit Leuven, 1998, p. 292-293; 317.

${ }^{17}$ SOLIS DE LOS SANTOS, José - Dos cartas desconocidas, p. 292, n. 50. 
que está de pé perante as suas portas ${ }^{18}$. Provavelmente Fernão Lopes Milão teria a intenção de a dedicar a Alonzo Ramirez de Prado pois o filho deste, numa missiva datada de 31 de Outubro de 1604, escreve que se alegra por Fernão Lopes Milão honrar seu pai com afecto e que traduza Tácito para português ${ }^{19}$. Mas esta associação de ideias numa mesma frase também pode ser coincidência.

Para a tradução portuguesa, Fernão Lopes Milão pode ter consultado os comentários de Justus Lipsius à Opera de Cornélio Tácito publicada na Oficina plantiniana em 1600 em Antuérpia ${ }^{20}$, o que justificaria de certo modo a troca de correspondência entre ambos. Todavia, esta hipótese não pode ser confirmada, uma vez que a obra de Tácito está omissa nos róis de livros existentes da livraria do referido literato.

Desconhecem-se os termos da carta de apresentação e das dúvidas de tradução de Fernão Lopes Milão a Justus Lipsio, apenas se conhece a curta resposta de Lipsio através da cópia duma carta de Fernão dirigida a Lorenzo Ramirez de Prado datada de Outubro de 1604, na qual estava inserta a de Lipsio datada de Lovaina de 13 de Julho daquele $a^{21}{ }^{21}$. Aparentemente os esclarecimentos de Lipsio sobre a passagem da separação dos bens maternos de Silano não satisfizeram Fernão Lopes Milão que, entretanto, pediu ajuda ao amigo Lorenzo de Prado para considerar as suas incertezas e cogitar ele próprio sobre a referida passagem, auxiliando-o no labor da versão portuguesa, já que era uma questão de heranças e consequentemente de Direito.

Lipsio, embora considerando ser uma solução rebuscada, aponta que Silano recebeu a maior parte dos bens da madrasta ${ }^{22}$. Por sua vez, Lorenzo Ramirez de Prado duvida da existência duma madrasta e espanta-se que Fernão Lopes Milão siga $\operatorname{Lipsio}^{23}$ neste particular. Esta questão conduziu a uma troca epistolar entre Lorenzo, Fernão, Lipsio e Martin del Rio.

${ }^{18}$ SOLIS DE LOS SANTOS, José - Dos cartas, p. 320-312.

${ }^{19}$ SOLIS DE LOS SANTOS, José - Dos cartas, p. 318-319.

${ }^{20}$ Existe a referência a um exemplar desta obra em quatro volumes na Livraria dos Teatinos cf. BNP, COD. 12935, Catálogo Metódico dos Livros de História por Francisco Franco Pereira, vol I, 1798, fl. 263 v.

${ }^{21}$ SOLIS DE LOS SANTOS, José - Dos cartas, p. 314-317.

${ }^{22}$ SOLIS DE LOS SANTOS, José - Dos cartas, p. 316-317.

${ }^{23}$ SOLIS DE LOS SANTOS, José - Dos cartas, p. 318-319. 
O professor Martin del Rio, amigo comum a Lorenzo Ramirez de Prado e Fernão Lopes Milão, manteve alguma correspondência com este último a partir de Valladolid em Dezembro de $1605^{24}$. Del Rio era o jurista do exército espanhol que impediu que os livros e bens de Lipsio fossem saqueados depois da ocupação de Lovaina pelas tropas de D. João de Áustria ${ }^{25}$, na década de 1570. Desde 1603 que ensinava Sagrada Escritura na Universidade de Salamanca ${ }^{26}$ e provavelmente foi aí que os três se encontraram.

Fernão Lopes Milão correspondeu-se pelo menos até Julho 1605 com Lorenzo Ramirez de Prado $^{27}$ e pelo que transparece das cartas, a amizade entre ambos era de longa data e íntima pois Fernão considerava-o "mitad de mi alma y su mejor pedazo". Conhecia inclusivamente os irmãos de Lorenzo e o pai que em alguma ocasião da vida o amparou e acolheu no seu círculo familiar, tal como the restituiu os bens e os da sua família ${ }^{28}$.

Fernão Lopes era um homem viajado, tendo-se deslocado principalmente a Castela onde esteve em vários lugares, entre eles em Valladolid, Medina del Campo, Madrid e Salamanca ${ }^{29}$. Desconhece-se quando estas viagens tiveram lugar, mas pode-se datar a estada em Salamanca no período entre 1603, altura em que Martin del Rio começou a ensinar Sagrada Escritura na Universidade, e Outubro de 1604, quando Fernão escreveu uma carta a Lorenzo Ramirez de Prado $^{30}$, já em Lisboa.

Quando se encontrava nos cárceres da Inquisição revelou que tinha um certo conhecimento musical. $\mathrm{O}$ acaso fez com que o seu companheiro de cela, Luís Ferreira, fosse cantor e numa das ocasiões vendo o pai a passar para prestar declarações na mesa do Santo Ofício, pediu ao companheiro de cárcere para cantar o In Te Domini Esperavi ${ }^{31}$ dando-lhe alento e simultaneamente estimulando-lhe a fé e esperança em Deus.

${ }^{24}$ SOLIS DE LOS SANTOS, José - Dos cartas, p. 286. Carta n ${ }^{\circ} 66$.

${ }^{25}$ SOLIS DE LOS SANTOS, José - Dos cartas, p. 292-293. Carta n 51.

${ }^{26}$ SOLIS DE LOS SANTOS, José - Dos cartas, p. 290.

${ }^{27}$ SOLIS DE LOS SANTOS, José - Dos cartas, p. 286. Carta $n^{\circ} 72$.

${ }^{28}$ SOLIS DE LOS SANTOS, José - Dos cartas, p. 315.

${ }^{29}$ IANTT, $I L$, proc. 2523 , fl. $138-138 \mathrm{v}$.

${ }^{30}$ SOLIS DE LOS SANTOS, José - Dos cartas, p. 314-317.

${ }^{31}$ IANTT, $I L$, proc. 2523, fl. 36. Este tema surge em vários compositores renascentistas nomeadamente de Josquin Des Prés (c. 1450-1521). 
Nos cárceres passava os domingos a escrever versos ${ }^{32}$, escrevendo também cartas ao Papa e ao rei, que trazia nas algibeiras com intenção de as enviar para o exterior pelo seu companheiro de cela, que as deveria entregar a Manuel Sanches ou a Gaspar Fernandes Penso. Para escrever aproveitava o papel dos confeitos, o do açúcar e do açúcar rosado que lhe davam, utilizava três penas e fazia tinta do fumo das candeias ${ }^{33}$. Esta denúncia de Luís Ferreira foi comprovada por uma revista às suas algibeiras onde foram encontrados 22 papéis e escritos em várias letras e quatro cadernos de oitavo ${ }^{34}$.

Pelo que foi dito e demonstrado Fernão Lopes Milão inseriu-se no humanismo português e europeu, interessou-se pelos autores da Época Clássica, pelas obras na sua língua de origem, pela partilha de experiências correspondendo-se com várias autoridades ibéricas e do Norte da Europa. Nesta altura os intelectuais integravam uma rede mais ou menos globalizada com contactos relativamente regulares cuja finalidade era a discussão de questões e temas, a difusão de novos conhecimentos, a circulação de obras e a partilha do conhecimento. Estava-se em pleno desenvolvimento científico e cultural, travado na Península pela ortodoxia religiosa e fiscalizado pela Inquisição.

\section{A biblioteca de Fernão Lopes Milão}

Em Março de 1607, no tempo em que toda a família Milão estava presa, o hortelão Pêro Gonçalves encontrou um saco com livros e papéis na chaminé duma casa que dava acesso ao pátio das casas de Henrique Dias de Milão ${ }^{35}$. Este achado foi comunicado ao confessor das flamengas que rapidamente

${ }^{32}$ IANTT, $I L$, proc. 2523 , fl. $35 \mathrm{v}$.

${ }^{33}$ IANTT, $I L$, proc. 2523, fl. 36v.-37. Sobre o uso de suporte e instrumentos de escrita ver MARQUILHAS, Rita - A Faculdade das Letras. Lisboa: Imprensa Nacional, 2000, p. 38; sobre comunicação entre os presos ver MEA, Elvira - A Inquisição de Coimbra no Século XVI. Porto: Fund. António de Almeida, 1997, p. 436-452.

${ }^{34}$ IANTT, $I L$, proc. 2523 , fl. $169 \mathrm{v} .-170$.

${ }^{35}$ IANTT, $I L$, proc. 2523 , fl. $87-88$. Este hortelão entrou por umas casas que davam serventia ao pátio da casa de Henrique Dias Milão e andando à procura de pregos para uma nora resolveu pesquisar também a chaminé, aí encontrou um saco de livros e papéis. Estas casas foram alugadas a António de Saldanha, mas estiveram sempre desocupadas e de fácil acesso à família Milão. 
deu conhecimento à Inquisição e entregou os livros. Não se apurou número exacto de obras encontradas ou de que tratavam, mas a avaliar pelo conteúdo do processo, trata-se dos livros deixados por Fernão Lopes Milão em sua casa, indicando-se de seguida o rol dos livros proibidos e alvo da censura pelos oficiais da Inquisição de Lisboa.

\section{Livros Proibidos ${ }^{36}$}

\begin{tabular}{|l|l|}
\hline \multicolumn{1}{|c|}{ Autores } & \multicolumn{1}{c|}{ Livros } \\
\hline (Leger Duchesne) $^{\text {Alçiatu }}$ & Farrago Poematum \\
\hline A7
\end{tabular}

${ }^{36}$ IANTT, IL, proc. 2523, fl. 179. Sobre livros proibidos ver RÉVAH, I. S. - La Censure Inquisitoriale Portugaise au XVIe Siècle. Lisboa: Instituto de Alta Cultura, 1960; PEREIRA, Isaías da Rosa - Notas Históricas acerca de Índices de Livros Proibidos e Bibliografia sobre Inquisição. Lisboa: s.n., 1976; SÁ, Artur Moreira de - Índices dos Livros Proibidos em Portugal no Século XVI. Lisboa, INIC, 1983; BUJANDA, J. M. de (ed.) - Index de l'Ínquisition Portugaise $(1547,1551,1561,1564,1581)$. Sherbrooke: Université de Sherbrooke, 1995.

${ }^{37}$ Proibido desde $1547 \mathrm{cf}$. Table des auteurs et ouvrages condamnés in BUJANDA J. M. de (ed.) - Index de l'Ínquisition Portugaise..., cit., p. 770.

${ }^{38}$ Esta obra e a de Cordero incluíam-se entre as obras de desafios proibidas desde 1581 cf. Table, cit., p. 767.

${ }^{39}$ Indexada em 1581 cf. Table, cit., p. 732.

${ }^{40}$ De Giovanni Battista Folengo, narra as aventuras burlescas dum frade que sai do convento para levar uma vida escandalosa, arrependendo-se mais tarde cf. AULTDUMESNIL, Éduard d' - Nouveau Dictionnaire d'histoire et Géographie anciennes et Modernes, $2^{\mathrm{a}}$ ed.. Paris: Lecoffre et fils, 1868, p. 541. Este autor foi indexado em $1561 \mathrm{e}$ 1581 cf. Table, cit., p. 734.

${ }^{41}$ Obra defesa desde 1547 cf. SÁ, Artur Moreira de - Índices dos Livros Proibidos em Portugal no Século XVI. Lisboa: INIC, 1983, p. 145 (transcrição do índice de 1547).

${ }^{42}$ Reservada desde 1581 cf. Table, cit., p. 717.

${ }^{43}$ Listado em 1561 cf. Table, cit., p. 763. 


\begin{tabular}{|l|l|}
\hline \multicolumn{1}{|c|}{ Autores } & \multicolumn{1}{c|}{ Livros } \\
\hline Luciani Samosatensis & $\begin{array}{l}\text { De Sectis } \\
\text { Deorum Dialogi }\end{array}$ \\
\hline Maquiavel $^{44}$ & Da Razam de Estado (em francês e italiano) \\
\hline Ovidio & Transmutationis ${ }^{45}$ (por Nicolau Agustini) $^{46}$ \\
\hline Petri Criniti & De honesta disciplina \\
\hline & De Juditys Nativitatum \\
\hline
\end{tabular}

Estes dezanove autores e obras reflectem os interesses do possuidor. Do rol fazem parte autores clássicos, humanistas e autores que se debruçaram sobre questões matemáticas, de Astrologia, Platonismo e Filosofia em geral, Política e Geografia, Poesia e auto-conhecimento. Trespassa das escolhas de Fernão a busca religiosa e a tentativa de encontrar respostas junto das fontes na sua origem, equilibrando ciência e religião. Mas também transparece uma tentativa de desconstrução do conhecimento com vista a encontrar uma maior proximidade do conhecimento ao objecto estudado.

Fernão Lopes Milão, para além destas obras proibidas que pretendia deixar a D. Nuno Álvares de Portugal, tinha ainda em hebraico toda a Bíblia em dez volumes pequenos que lhe dera o mestre Manuel Correia e gramáticas ${ }^{47}$ desta língua. Contava, portanto com pelo menos 22 obras, ou 31 livros.

Mas o seu espólio era consideravelmente superior, pois Fernão declarou à Inquisição que possuía os principais livros de todas as ciências, excepto Medicina, por onde estudava ${ }^{48}$. Isto significa que a lista elaborada pelos oficiais do Santo Ofício representa uma pequena parcela da livraria de Fernão Lopes Milão na medida em que reflecte a finalidade de dar conta dos livros defesos que pudessem ser uma agravante às possíveis penas dos encarcerados. Por conseguinte, é credível o testemunho de Tomás Spret quando afirmou que Fernão Lopes Milão tinha uma grande livraria ${ }^{49}$.

${ }^{44}$ Autor listado em 1561, 1581 e 1597 cf. Table, cit., p. 748; SÁ, Artur - Índices dos Livros, cit., p. 806.

${ }^{45}$ Identificável com Metamorphoses proibido desde 1581 cf. Table, cit., p. 755.

${ }^{46}$ Proibido em $1581 \mathrm{cf}$. Table, cit., p. 727.

${ }^{47}$ IANTT, $I L$, proc. 2523 , fl. 166v.-167.

${ }^{48}$ IANTT, $I L$, proc. 2523 , fl. $161 \mathrm{v}$.

${ }^{49}$ IANTT, $I L$, proc. 2523, fl. 15. Tomás Spret era um caixeiro inglês de António de Cárceres, tio de Fernão Lopes e que estivera uns tempos acomodado com a família Milão. 
A maior parte dos livros foi comprada a frei António de Sequeira, religioso de S. Domingos, outras obras ficaram de frei António de Sousa, bispo de Viseu, adquiridas mais tarde aos livreiros Estêvão Lopes e António Ribeiro $^{50}$, incluindo provavelmente alguns dos livros defesos. Esta situação é bem demonstrativa da circulação e transacção de obras interditas de forma mais ou menos clandestina, que incluía os livreiros cujas lojas de Lisboa não eram fiscalizadas ${ }^{51}$.

No que se refere a manuscritos, Fernão Lopes tinha ainda um número indeterminado de cadernos alvo do escrutínio de João Correia ao serviço da Inquisição de Lisboa ${ }^{52}$. De acordo com o parecer deste último foram submetidos à censura da Igreja os cadernos 18, 19, 22 e 23, embora se mencionem outros de numeração inferior onde também constam pequenas frases e abreviaturas que podiam ser entendidas como heréticas e de crime de lesa-majestade. Isto quer dizer que existiam pelo menos 23 cadernos cujo número de páginas se desconhece.

Entre estes cadernos poderiam encontrar-se os manuscritos dos muitos livros iniciados por Fernão Lopes de temáticas diversas ${ }^{53}$. Este começou a escrever um livro Do Perfeito Governo por mandado de Ramires do Prado e D. Álvaro de Benevides, ouvidores da Câmara. Para isso traduziu Cornélio Tácito sobre quem fez uns discursos interessando-se entretanto pela Poesia sobre a qual escreveu um tratado. Também iniciou apontamentos para uns discursos sobre a Sagrada Escritura do Génesis ao Apocalipse entrecruzando-os com discursos profanos imitando o jesuíta Martino de Roa. Escreveu tratados de matemática e fazia figuras geométricas. Tomando como exemplo o Padre Ribeiro, estudou a Sagrada Escritura em questões matemáticas debruçando-se sobre a contagem do tempo, a Geometria,

${ }^{50}$ IANTT, IL, proc. 2523, fl. 168. Estêvão Lopes encomendava obras a Pedro Craesbeeck e Manuel de Lira; António Ribeiro custeava edições, imprimia livros e foi tipógrafo da Casa Real cf. GUEDES, Fernando - Os Livreiros em Portugal. Lisboa: Verbo, 1993, p. 28-29; ver também Anselmo, António Joaquim - Bibliografia das Obras Impressas em Portugal no Século XVI. Lisboa, Of. Biblioteca Nacional, 1926, p. 287-288; LIMA, Durval Pires deOs primeiros livros e livreiros de Lisboa. Lisboa: CML, 1942.

${ }^{51}$ MARQUILHAS, Rita - A Faculdade das Letras, cit., p. 152-156. Esta autora dá conta duma única visita do Santo Ofício às livrarias em 1606 com a finalidade de apreender obras clandestinas.

${ }^{52}$ IANTT, $I L$, proc. 2523 , fls. 111-112.

${ }^{53}$ IANTT, $I L$, proc. 2523, fls. 161v.-162. 
a fábrica e grandeza do Templo e da Arca. Os seus interesses incidiam sobre a Luz que Deus fez no princípio do Mundo e na forma de contar os anos até Noé, e dele até Abraão. Nestes tratados limitou-se a comentar com base na Matemática, em matérias da sua profissão e nas autoridades como S. Tomás, pois não estudara Artes, Teologia ou outra ciência ${ }^{54}$. Outrossim escreveu um livro sobre a tradição dos livros de Santo Agostinho Cidade de Deus e uns discursos sobre o Salmo 72, para além disso escreveu a obra Do Perfeito Secretário a pedido de João Brandão Soares onde tratou da mentira ${ }^{55}$. As obras de autoria de Fernão Lopes Milão seriam portanto cerca duma dezena sobre temáticas tão diversas como Política, Direito, Poesia, Teologia, Filosofia, ou Matemática.

Mas voltando aos impressos, há que convir que aquele estudioso deveria ter em sua posse um exemplar da Cidade de Deus de Santo Agostinho à qual dedicou um livro, os Anales de Tácito que pretendia verter para português ${ }^{56}$ e que para além disso também devia ter gramáticas de outras línguas como o grego e o latim. As estantes da sua livraria deveriam ainda alinhar os principais livros de Matemática e Geometria, as disciplinas de sua eleição e formação, o que é corroborado pelos seus testemunhos ao Santo Ofício.

Apesar de tudo apontar para uma mais vasta livraria de Fernão Lopes Milão, apenas se pode comprovar a existência de 22 impressos e 23 manuscritos, embora se possa indicar que o seu espólio ultrapassava a meia centena de livros tendo em conta que a Bíblia tinha 10 volumes. Para se ter um termo de comparação, uma das maiores bibliotecas particulares conhecidas de finais do século XVI em Portugal contava com 900 volumes e pertencia ao canonista Luís Correia ${ }^{57}$; por volta de 1625 o cristão-novo Miguel

${ }^{54}$ Esta temática parece ser recorrente pois também no séc. XVII Jacob Yeuda Leon Hebreu escreveu Retrato del Templo de Salomon e Tratado del Arca del Testamento entre outros. Estas duas obras e outra intitulada Tratado de los Cherubim existem na Biblioteca Nacional de Portugal com as cotas Res. 1050 P e Res. 19 V.

${ }^{55}$ IANTT, $I L$, proc. 2523 , fls. $164 \mathrm{v} .-165$.

${ }^{56}$ SOLIS DE LOS SANTOS, José - Dos cartas..., cit., p. 316-317. De acordo com Lipsio, Fernão Lopes estava a traduzir a obra de Tácito por volta de 1604.

${ }^{57}$ MARQUES, A. H. de Oliveira - As Instituições de Cultura in DIAS, João Alves (coord.) - Nova História de Portugal, vol. V. Portugal do Renascimento à Crise Dinástica, Lisboa: Presença, 1998, p. 482-483. 
Lobo $^{58}$ possuía uma livraria com cerca de oitenta exemplares impressos e manuscritos; e o religioso Frei Diogo de Murça, tinha uma biblioteca com 94 livros no colégio da Penha Longa, que fundou, e no Colégio de S. Bento de Coimbra tinha ainda mais 284 obras $^{59}$.

Fernão Lopes Milão não se destacou apenas pelo seu humanismo e empreendorismo nas Letras e Matemáticas. Este mercador salientou-se também pela história familiar e pela constante busca de liberdade que se traduziu em diversas tentativas de saída clandestina de Portugal e dos espaços controlados pela Inquisição. Vejamos a interessante história das tentativas de fuga dos Milão antes e depois de presos, registada ao pormenor na Inquisição de Lisboa permitindo desse modo reconstituir as diversas cenas, quase cinematográficas.

\section{As tentativas e a fuga dos Milão para Hamburgo}

Corria o ano de 1606 quando Henrique Dias Milão e a esposa Guiomar Gomes decidiram abandonar Portugal e juntar-se à filha Beatriz Henriques ${ }^{60}$ casada com Álvaro Dinis ou Samuel Jachia ${ }^{61}$ em Hamburgo.

Esta decisão deveu-se ao facto de Henrique Dias Milão se ver a braços com uma ameaça de prisão e sequestro de bens pela justiça civil ${ }^{62}$, logo após

${ }^{58}$ IANTT, $I L$, proc. 3003. Trata-se de Miguel Lobo que vivia de sua fazenda e sabia a língua latina.

${ }^{59}$ CARVALHO, Joaquim - Obra Completa, vol. II História da Cultura. Lisboa: Fundação Gulbenkian, 1982, p. 569-638.

${ }^{60}$ IANTT, $I L$, proc. 10758, fl. 86v. (ausente). A sua estátua foi relaxada à justiça secular no auto de Fevereiro de 1617 na Ribeira em Lisboa.

${ }^{61}$ Álvaro Dinis ou Samuel Jachia era um líder espiritual em Hamburgo, reunindo em sua casa os cristãos-novos em sinagoga. Sobre os Milão e Jachia ver FRADE, Florbela Veiga - Importância Social e Religiosa das Famílias Milão-Dinis em Portugal e em Hamburgo. Internationales Kolloquium Portugal, Hamburg und die Deutschsprachige Welt Wärend der Europäischen Expansion nach Übersee (16. bis 18. Jahrhundert). Jun. 2009, Friedrich Edelmayer, Alfred Kohler, José Carlos Rueda Fernández (ed.) - Munique (no prelo); BEN BRITH, Joseph - Die Odyssee der Henrique-Familie. Frankfurt am Main: Peter Lang, 2001; STUDEMUND-HALÉVY, Michael - Biographisches Lexicon der Hamburger Sefarden. Hamburg: Hans Christians Verlag, 2000.

${ }^{62}$ IANTT, $I L$, proc. 2523 , fl. $139-139 \mathrm{v}$. 
a prisão de Gabriel Ribeiro ${ }^{63}$, seu sócio em negócios. Ambos arremataram o contrato das terças e, aparentemente, o negócio correu mal. Além disso um seu criado, chamado Francisco Barbosa, resolveu denunciar toda a família à Inquisição.

A actividade principal da família era a mercância e a finança, sendo a casa comercial encabeçada por Henrique Dias de Milão. Quando em 1606 a família resolveu sair de Portugal, pensaram em deixar Paulo de Milão em Lisboa na gestão dos negócios, enquanto que Fernão Lopes iria para Madrid ${ }^{64}$, mantendo-se os laços que os uniam à Península Ibérica.

A importância de Henrique Dias Milão no Reino era considerável e isso pode avaliar-se também pelo facto de ter sido avisado com alguma antecedência do perigo que corria. A família foi alertada pelo alcaide que tinha o mandato, pelo escrivão Madeira, por Vasco Peres Mendes que tentou atrasar a sua execução e pelo próprio executor-mor, Manuel Gomes de Elvas $^{65}$. O filho Fernão Lopes Milão teve acesso ao primeiro mandado através de António Camelo, o tesoureiro das Terças, e também teve conhecimento do segundo mandado cujo executor dos Contos era António Serrão ${ }^{66}$.

Os Milão tinham-se mudado recentemente para uma casa em Alcântara na freguesia da Ajuda junto às quintas de Algés e dum mosteiro donde tinham acesso ao mar $^{67}$. A casa apalaçada tinha uma zona térrea e um piso superior com pátio interior e oferecia as condições necessárias ao alojamento da vasta prole do casal. Aí residiam Leonor Henriques ${ }^{68}$, casada com o licenciado

${ }^{63}$ Sobre Gabriel Ribeiro e família Milão ver SALOMON, Herman Prins - Portrait of a New Christian Fernão Álvares Melo. Paris: FCG, 1982, p. 107-108; COELHO, António Borges - Questionar a História, V. Lisboa: Caminho, 2001, p. 123-124; RÉVAH, I. S. - Uriel da Costa et les Marranes de Porto. Paris: FCG, 2004, p. 302-317.

${ }^{64}$ IANTT, $I L$, proc. 2523 , fl. $134 \mathrm{v}$.

${ }^{65}$ IANTT, $I L$, proc. 2523, fl. 139. Manuel Gomes de Elvas foi um dos financiadores cristãos-novos do rei para o provimento da armada da Índia de 1605 no valor de 200.000 cruzados. Em 1609, com Heitor Mendes de Brito, Nuno Dias Carlos, Francisco Duarte Ximenes emprestaram ao rei 33.500 cruzados para as naus em letras de câmbio passadas a Goa e com interesse. Em 1610 os mesmos proveram as naus da Índia no valor de 71.667 sendo reembolsados com o dinheiro do Perdão Geral. Cf. BOYAJIAN, James - Portuguese Trade in Asia under the Habsburgs, 1580-1640. Baltimore: John Hopkins University Press, 1993, p. 92. Ver também SALOMON, Herman - Portrait, cit., p. 94, n. 87.

${ }^{66}$ IANTT, $I L$, proc. 2523, fl. 139.

${ }^{67}$ IANTT, $I L$, proc. 2499, fl. 143.

${ }^{68}$ IANTT, $I L$, proc. 9389. 
Henrique Rodrigues, seu primo que tinha ido a Roma buscar dispensa; Isabel Henriques ${ }^{69}$; Branca Rodrigues; Paulo de Milão ${ }^{70}$; Fernão Lopes Milão ${ }^{71}$; Gomes Rodrigues Milão ${ }^{72}$ vindo recentemente de Pernambuco (onde esteve com o cunhado e os irmãos Manuel Cardoso Milão e António Dias Milão) esposado com a prima Beatriz Rodrigues ${ }^{73}$. Por seu turno Ana de Milão ${ }^{74}$, casada com Manuel Nunes de Matos $^{75}$, estante no Brasil, mudara-se recentemente para outra casa com os filhos e uma criada de confiança.

Também se alojou nas mesmas casas António Dias de Cárceres, irmão de Henrique Dias Milão recentemente chegado do México em negócios e fugido da Inquisição Espanhola ${ }^{76}$, conseguindo sair para parte incerta antes das prisões.

Sobre o mesmo tecto viviam vários criados, destacando-se pelos laços de parentesco com os Milão o denunciante da família ao Santo Ofício, Francisco Barbosa, e a irmã Violante que acompanhou Beatriz Henriques a Hamburgo ${ }^{77}$. Dos escravos há a destacar Vitória Dias, uma chinesa de mais de 50 anos forra há cerca de cinco $^{78}$, mas ainda ao serviço de seus antigos donos, acompanhando-os sempre.

Em Outubro de 1606 a família Milão preparou-se para a fuga que teve lugar a 28 desse mês, sendo descrita em pormenor nos registos inquisitoriais. Durante dois ou três dias Fernão Lopes de Milão escondeu-se em casa de Vicente Furtado, no Chiado, onde foram visitá-lo Jorge Rodrigues Jorge e Francisco de Almeida que, por sua vez, tinha Leonor Henriques escondida em sua casa ${ }^{79}$.

${ }^{69}$ IANTT, $I L$, proc. 6984.

${ }^{70}$ IANTT, $I L$, proc. 3338.

${ }^{71}$ IANTT, $I L$, proc. 2523.

${ }^{72}$ IANTT, $I L$, proc. 2499.

${ }^{73}$ IANTT, $I L$, proc. 9407.

${ }^{74}$ IANTT, $I L$, proc. 279.

${ }^{75}$ IANTT, $I L$, proc. 10600.

${ }^{76}$ António Dias de Cárceres foi preso pela Inquisição do México com a mulher, que foi entregue à justiça secular, e uma filha chamada Leonor que continuava no México cf. TT, $I L$, proc. 2423, fl. 134.

${ }^{77}$ IANTT, $I L$, proc. 6671 , fl. 130.

${ }^{78}$ IANTT, $I L$, proc. 3331 , fl. $47-47 \mathrm{v}$.

${ }^{79}$ IANTT, $I L$, proc. 3333, fl. 30-31. Vicente Furtado era primo de Álvaro Dinis casado recentemente com uma das filhas de Henrique Dias Milão. 
Francisco de Almeida e Maria Henriques, prima dos Milão, viviam na casa do boticário do Hospital Real e albergaram na Cutilaria em Lisboa, durante cerca de 20 dias, Leonor e seu irmão Gomes Rodrigues de Milão ${ }^{80}$. O parentesco foi razão bastante para o casal correr o risco de acolher fugitivos.

Dois dias antes Fernão Rodrigues Penso foi a casa de Gomes Rodrigues à Cordoaria Velha e aí combinou com Fernão Lopes e Vicente Furtado juntarem-se no dia da fuga às 11 horas junto à ponte de Alcântara, para daí irem a casa de Henrique Dias Milão que tinha uma ponte para o mar donde embarcariam numa fragata ${ }^{81}$.

$\mathrm{Na}$ véspera, o meirinho do porto de Lisboa ao inspeccionar os navios viu camas e fato de passageiros no navio Anjo que ia para La Rochelle, o mestre Sechão foi preso $^{82}$ e foi provavelmente nesta altura que na Inquisição tiveram conhecimento da possibilidade de fuga dos Milão numa nau de França.

A tentativa de fuga deu-se de sexta-feira para sábado, 28 de Outubro de 1606, distribuindo-se as pessoas por uma falua e uma barca ${ }^{83}$. Nessa noite, Fernão Rodrigues Penso dirigiu-se com seu primo Gaspar Fernandes Penso $^{84}$ à casa de Henrique Dias Milão, onde já se encontravam as pessoas a embarcar ${ }^{85}$.

Num navio iam cinco acompanhantes: Vicente Furtado, filho de Duarte Furtado e primo de Álvaro Dinis; António Mendes cristão-novo casado e morador à Cutelaria; Manuel Sanches cristão-novo, solteiro e filho de Bento Henriques (criado de Henrique Dias Milão que depois de passar pela Inquisição foi para Hamburgo); Gaspar Fernandes Penso, cristão-novo, tratante, casado com uma filha do fanqueiro Gama, morador ao Pelourinho Velho; Fernão Rodrigues Penso, solteiro, filho de Fernão Rodrigues Penso que morava em Badajoz, primo do anterior. Todos os envolvidos sabiam das dívidas ao rei e do motivo porque saíam do reino ${ }^{86}$.

\footnotetext{
${ }^{80}$ IANTT, $I L$, proc. 2499 , fls. $264-264 \mathrm{v}$.

${ }^{81}$ IANTT, $I L$, proc. 17.562 , fl. $13 \mathrm{v}$.

${ }^{82}$ IANTT, $I L$, proc. 17.562 , fl. $5-6$.

${ }^{83}$ IANTT, $I L$, proc. 17.562, fl. 4-4v. As designações para os tipos de navio usado divergem nos vários testemunhos. Refere-se falua, barca e fragata.

${ }^{84}$ IANTT, $I L$, proc. 17.562 , fl. 16-16v.

${ }^{85}$ IANTT, $I L$, proc. 17.562 , fl. 14.

${ }^{86}$ IANTT, $I L$, proc. 3333 , fl. $20 \mathrm{v}$
} 
Os cinco estavam armados: Fernão Rodrigues Penso levava uma espada e uma adaga, Paulo de Milão carregava duas espingardas, Gaspar Penso tinha um montante ${ }^{87}$ e por fim, António Mendes transportava uma rodela ${ }^{88}$ e uma espada ${ }^{89}$, como protecção contra perseguidores que impedissem a fuga. Fernão Lopes Milão justificou o recurso a estes homens como defesa contra castelhanos ou outros que pudessem barrar a embarcação já que o motivo da saída ilícita seria a dívida ao rei que ascendia aos 20.000 réis $^{90}$.

Entre a meia-noite e a uma da noite os familiares do Santo Ofício juntaram-se aos oficiais régios e amarraram a sua embarcação a um navio ancorado no porto. Aí ficaram de vigia até avistarem os dois navios mandando-os parar para fazer as suas diligências e ordenaram aos homens para entregarem as armas ${ }^{91}$. Na falua seguindo em direcção a S. João iam cinco homens armados com duas espingardas carregadas, um montante, uma espada de seis palmos, mais quatro espadas e uma rodela. Na barca, que foi logo tomada pelos guardas e familiares do Santo Ofício, ia Fernão Lopes Milão vestido com saia de malha acompanhando as mulheres ${ }^{92}$.

Mas quem eram os homens armados? E porque o faziam?

António Mendes ia a acompanhar a família Milão porque Fernão Lopes lho pedira sabendo por este das dívidas de Henrique Dias Milão aos Contos do Reino. Tal como os outros, foi preso na enseada de Santa Catarina pelos familiares da Inquisição e pelo alcaide do mar de Belém entregando então os 30.000 réis que tinha ao juiz do fisco ${ }^{93}$, facto que foi mais tarde usado para demonstrar uma tentativa de suborno. António Mendes, também conhecido por António Mendes Cardoso, morava à Santa Justa com sua esposa, uma prima dos Milão ${ }^{94}$, chamada Marquesa Cardoso. Depois de libertado pelo Santo Ofício dirigiu-se a Santa Comba Dão e daí a Toledo ${ }^{95}$. Contudo, segundo uma carta de denúncia à Inquisição de Coimbra, António Mendes

\footnotetext{
${ }^{87}$ Montante: espada pesada usada com duas mãos.

${ }^{88}$ IANTT, $I L$, proc. 17.562 , fl. 13. Rodela: escudo redondo.

${ }^{89}$ IANTT, $I L$, proc. 17.562 , fl. $17 \mathrm{v}$.

${ }^{90}$ IANTT, $I L$, proc. 2523 , fl. $134 \mathrm{v}$.

${ }^{91}$ IANTT, $I L$, proc. 17.562 , fl. 6v.-7.

${ }^{92}$ IANTT, $I L$, proc. 17.562 , fl. $3-3 \mathrm{v}$.

${ }^{93}$ IANTT, $I L$, proc. 17.562 , fl. 9-10.

${ }^{94}$ IANTT, $I L$, proc. 2523 , fl. $134 \mathrm{v}$.

${ }^{95}$ IANTT, Inquisição de Coimbra, Lo 295, fls. 734-746.
} 
e a esposa foram levados por seu cunhado Francisco de Cárceres a Aveiro ou ao Porto onde embarcaram ${ }^{96}$ para fora do reino.

Outro dos envolvidos na fuga foi António Barbosa ${ }^{97}$, de 29 anos, que acompanhava Henrique Dias, a mulher, as filhas, Fernão Lopes, Gomes Rodrigues, Beatriz Rodrigues, Vitória Dias escrava cativa e a ama Beatriz Rodrigues, que se renderam e não resistiram. De acordo com a sua descrição dos acontecimentos, noutro barco seguiam Paulo de Milão, António Mendes parente de Henrique, os Pensos, Vicente Furtado e Manuel Sanches ${ }^{98}$, estes acompanhavam a família para depois voltarem à cidade. Todos foram presos por João Gonçalves por auxílio a Henrique Dias Milão, devedor de 50.000 cruzados do Contrato dos Terços havendo por isso um mandado de captura ${ }^{99}$ sobre o dito.

Vicente Furtado também tinha sido contactado pelo amigo Fernão Lopes para o acompanhar à Flandres informando-o das dívidas à Casa dos Contos. Vicente não o fez por dinheiro e assim que foram descobertos entregaram as armas sem resistência. No seu relato diz ainda que António Mendes entregou ao juiz do fisco um saco com dinheiro ${ }^{100}$.

Manuel Sanches um jovem de 20 anos, natural de Olivença e criado de Henrique Dias Milão há 8 anos, também testemunhou a prisão sem resistência e declarou ainda ter visto António Mendes dar ao juiz do fisco 30.000 réis e Leonor Henriques uma cadeia de ouro que valia mais de 11.000 réis $^{101}$. Manuel Sanches era caixeiro de Henrique Dias Milão e filho de Bento Henriques, cristão-novo que fora preso pelo Santo Ofício e estava em Calais ${ }^{102}$.

Manuel Sanches tomou o nome Manuel Henriques e foi mais tarde alvo do pedido de diligência dos inquisidores da Índia a que os inquisidores de Sevilha e de Coimbra deram resposta em 1609. Fora criado de Fernão Lopes e no Porto escreveu ao pai Bento Sanches ou Bento Henriques morador em Cádiz (este acompanhara Beatriz Henriques a Hamburgo).

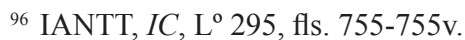

${ }^{97}$ IANTT, $I L$, proc. 286. Foi relaxado à justiça secular.

${ }^{98}$ IANTT, $I L$, proc. 17.562 , fl. $22 \mathrm{v} .-23$.

99 IANTT, $I L$, proc. 3338 , fls. 142v.-143.

${ }^{100}$ IANTT, $I L$, proc. 17.562 , fl. 10-11.

${ }^{101}$ IANTT, $I L$, proc. 17.562 , fl. $20-21 \mathrm{v}$.

${ }^{102}$ IANTT, $I L$, proc. 3338 , fls. $179-179 \mathrm{v}$.
} 
A Inquisição de Sevilha interceptou duas cartas de Manuel Henriques datadas de 1608 e de 1609 remetidas do Porto onde refere ter retornado a Portugal ido de Hamburgo contra a vontade de Álvaro Dinis. Pedia que a resposta fosse dada a Jácome Gomes Palácios ${ }^{103}$. Ou seja, depois da prisão Manuel Sanches foi para Hamburgo mas resolveu voltar a Portugal apesar de todos os conselhos em contrário.

Outro dos intervenientes, Fernão Rodrigues Penso estava em Lisboa para embarcar para a Índia e foi preso porque o seu amigo Fernão Lopes lhe pediu para o acompanhar e aos pais numa fragata para embarcarem num navio francês surto na baía de Santa Catarina. O destino era a Flandres e Hamburgo, pois tinham muitas dívidas ao rei. Na fragata, para além dele próprio, ia o primo Gaspar, António Mendes Cardoso, Vicente Furtado, Paulo de Milão e o barqueiro. De acordo com o seu testemunho, Manuel Sanches ia com as mulheres ${ }^{104}$ no outro navio.

Gaspar Fernandes Penso, primo do anterior, foi quem mais padeceu nos cárceres da Inquisição. Era um cristão-novo de 24 anos, natural de Badajoz mas morador em Lisboa nas Carneçarias Velhas onde a mãe tinha loja de coisas da Índia. Casou com Beatriz da Gama e tinha um filho de 5 meses ${ }^{105}$, quando foi preso. Gaspar foi torturado em 1611, sendo despojado da roupa, sentado no lugar da polé com as mãos atadas atrás, foi-lhe posta uma correia e atado com cordel. Depois de posto o calabre foi levantado até à roldana e deixado cair por quatro vezes, na quinta vez foi baixado à mão pois o médico, que assistia a tudo, alertou que o atormentado não aguentaria mais. Gaspar gritou sempre ser bom cristão ${ }^{106}$. Depois de tal zelo nos tratamentos, Gaspar ficou aleijado dum braço, mas mesmo assim foi condenado a três anos nas galés. Mais tarde teve de pedir autorização para ser dispensado do cumprimento da pena por impossibilidade física, sendo-lhe esta comutada contra o pagamento de 100.000 réis. Não obstante, Gaspar manteve-se até Maio de 1612 ao serviço nas galés ${ }^{107}$. Os cinco homens envolvidos na fuga

\footnotetext{
${ }^{103}$ IANTT, $I C, \mathrm{~L}^{\circ} 293$, fls. 639-641.

${ }^{104}$ IANTT, $I L$, proc. 17.562 , fl. 11-12.

${ }^{105}$ IANTT, $I L$, proc. 17.562 , fl. $1-2 \mathrm{v}$. (geneal.)

${ }^{106}$ IANTT, $I L$, proc. 17.562 , fls. não numerados.

${ }^{107}$ IANTT, $I L$, proc. 17.562 , fls. n. n.
} 
foram libertados depois de pagarem as custas ${ }^{108}$, no entanto uns em melhores condições que outros.

Depois do auto-da-fé na Ribeira em Maio 1609, em que o patriarca da família e o seu criado foram queimados e toda a família saiu penitenciada, Paulo de Milão conseguiu fugir do Bairro da Penitência. A 20 de Agosto de 1609 quando três oficiais faziam diligência no Bairro de Santa Marinha, Paulo de Milão surgiu-lhes vestido com uma capa e carapuça na cabeça, umas ceroulas pretas largas e armado de espada de fecho atacou-os e conseguiu fugir rua abaixo ${ }^{109}$.

Passados meses, em 21 de Novembro, um familiar do Santo Ofício reconheceu Paulo de Milão na rua e prendeu-o por ir sem hábito penitencial. Levou-o ao inquisidor que o mandou entregar à cadeia. Na altura da sua prisão Paulo tinha uma espada de fechos com seis palmos e meio, esta com o fecho corrido ficava com oito palmos ${ }^{110}$.

No dia 10 de Dezembro de 1609, Paulo de Milão foi solto do Limoeiro e no dia 20 de Janeiro de 1610 tinha já fugido de novo do Bairro de Santa Marinha pois quando o alcaide das Escolas Gerais foi a sua casa apenas encontrou o hábito penitencial dobrado ${ }^{111}$. Vamos encontrá-lo mais tarde em Hamburgo.

A fuga frustrada de Isabel Henriques, irmã de Paulo de Milão, foi acidentada. A tia Ana de Milão tinha chamado Isabel várias vezes de Antuérpia e por conseguinte a sua saída num navio inglês foi negociada por Manuel Cardoso $^{112}$ um moço de 14 anos filho de Simão Rodrigues, servidor dos Milão. No dia 4 de Março de 1610 Manuel acompanhou Isabel, Vitória e as duas crianças pequenas de Ana de Milão a Xabregas. Chegados ao mosteiro de S. Francisco de Xabregas - depois de terem estado sentados junto ao cais da Madre de Deus - desceram os degraus de pedra até ao mar para embarcarem no barco em direcção à nau inglesa que os esperava. Quando do barco os dois ingleses lançaram a prancha e os esperavam, foram mandados parar pelo Santo Ofício. Os ingleses remaram para o mar e as restantes

\footnotetext{
${ }^{108}$ IANTT, $I L$, proc. 17.562 , fl. 25 .

${ }^{109}$ IANTT, $I L$, proc. 3338, fls. 207-208.

${ }^{110}$ IANTT, $I L$, proc. 3338 , fls. $209-209 \mathrm{v}$.

${ }^{111}$ IANTT, $I L$, proc. 3338 , fls. $211-211 \mathrm{v}$.

${ }^{112}$ IANTT, $I L$, proc. 6984 , fl. $54-54 \mathrm{v}$.
} 
pessoas foram presas e entregues nas Escolas Gerais ${ }^{113}$. Aí, as duas crianças de Ana de Milão ficaram na casa da avó ${ }^{114}$ causando algum desgosto ao tio Fernão Lopes Milão. Passados uns meses Isabel e Vitória foram soltas, pagaram então 20 cruzados, não podendo sair do reino sem licença ${ }^{115}$.

Mais tarde, Guiomar Dias, os seus filhos e sobrinha foram presos nas Escolas Gerais. Ela foi considerada a mentora da tentativa de fuga de Isabel Henriques e Vitória Dias para Antuérpia e por Paulo de Milão conseguir fugir. Todos ficaram confinados só podendo sair para o Bairro Penitencial depois de darem de fiança 200.000 réis ou 1.000 cruzados $^{116}$. Não se sabe se a família chegou a pagar tal valor.

\section{Uma Evasão do Bairro Penitencial de Lisboa}

O Bairro Penitencial, ou Escolas Gerais, ainda hoje se pode identificar geograficamente na onomástica de Lisboa. Nos séculos XVI e XVII era um espaço controlado pelos oficiais do Santo Ofício que garantiam a segurança dos penitenciados a sentenças espirituais ou que tivessem problemas de saúde e necessitando de cuidados que os cárceres não ofereciam.

Pelo que se pode depreender dos cadernos do promotor ${ }^{117}$, e dos processos inquisitoriais, o Bairro Penitencial era constituído por casas habitadas pelos sentenciados que já tinham cumprido as suas penas de cárcere e participado nos autos-da-fé, cumprindo a posterior doutrinação na fé decretada pelo Tribunal e constante da sentença. Por doutrinação entendia-se a participação em todas as missas, ouvir as pregações, comungar e confessar-se, rezar as orações listadas pela Mesa do Conselho da Inquisição, fazer alguns jejuns, não esquecendo também a guarda do domingo. A vigilância doutrinal estava a cargo dum clérigo que no fim passava uma certidão constante dos processos onde atestava que o indivíduo estava convenientemente doutrinado na fé.

\footnotetext{
${ }^{113}$ IANTT, $I L$, proc. 3331 , fl. $75-76$; id., proc. 6984 , fl. $54-54 \mathrm{v}$.

${ }^{114}$ IANTT, $I L$, proc. 2523 , fl. $234 \mathrm{v} .-235$.

${ }^{115}$ IANTT, $I L$, proc. 3331, fl. 78v.-79; id., proc. 6984, fl. 58.

${ }^{116}$ IANTT, $I L$, proc. 6671 , fl. $190-190 \mathrm{v}$.

${ }^{117}$ IANTT, IL, Livros 192-258, que não inclui todo o século XVII.
} 
Só com esta certidão o sentenciado poderia requerer que lhe fosse retirado o hábito penitencial e depois libertado na sociedade.

As Escolas Gerais, ou Quinta de Santa Marinha, foram palco duma fuga aparatosa - pelo número de pessoas envolvidas e pela raridade do feito entre 16 e 22 de Abril de 1610. De acordo com as declarações do alcaide Jorge da Costa aos inquisidores ${ }^{118}$, fugiram na noite de 21 para 22 de Abril as seguintes pessoas: Bento Rodrigues, a mulher Mor Rodrigues e a filha Violante Francesa; Pascoal Rodrigues e sua mulher Leonor Cardosa; Leonor Rodrigues, mulher de Francisco Sanches, com a enteada Ana Martins e a filha Isabel Dias. Para além deles o alcaide acabou por dar conta da fuga de Fernão Lopes Milão que teria visto no dia 16, mas cujo paradeiro todos desconheciam inclusivamente a sua mãe.

Este grupo de dez pessoas conseguiu perpetrar o que talvez milhares de pessoas tentaram ao longo de séculos e não conseguiram, ou seja, abandonaram as suas casas de penitência com os seus parcos haveres de reclusos. Alguns deixaram os seus hábitos penitenciais e coisas de pouca valia, outros, como Pascoal Rodrigues e Leonor Cardoso deixaram os seus bens mais preciosos: os dois filhos. Já Fernão Lopes Milão optou por levar consigo o hábito penitencial. Não podemos apurar com exactidão os locais de acolhimento, sendo mera especulação indicar a França como destino já que a maior parte dos envolvidos tinha laços fortes com este país.

Pode causar alguma estranheza verificar que um dos casais envolvidos na fuga deixou no local de reclusão os seus próprios filhos. O porquê de tal escolha só é compreensível se atentarmos no seguinte: Pascoal Rodrigues ${ }^{119} \mathrm{e}$ Leonor Cardoso ${ }^{120}$ foram presos com o filho mais velho Nicolau Rodrigues ${ }^{121}$ de 12 anos. Pela sessão de genealogia sabemos que tinham uma filha mais nova e pelos cadernos do promotor sabemos que esta se encontrava em sua companhia no Bairro Penitencial. Tal como eles, foram presos pela mesma altura vários membros da família de Pascoal Rodrigues e que deveriam estar também no Bairro Penitencial cumprindo as suas sentenças, nomeadamente

\footnotetext{
${ }^{118}$ IANTT, IL, L ${ }^{\circ} 206$, fls. 674-675.

${ }^{119}$ IANTT, $I L$, proc. 3336.

${ }^{120}$ IANTT, $I L$, proc. 9390.

${ }^{121}$ IANTT, $I L$, proc. 10588.
} 
dois dos seus irmãos. Trata-se de Páscoa Ferreira ${ }^{122}$ e António Ferreira ${ }^{123}$ - cuja esposa Leonor Rodrigues ${ }^{124}$ foi relaxada no auto de 1609 - e vários sobrinhos, alguns também meninos, filhos deste último, chamados Luís Ferreira ${ }^{125}$, Isabel da Conceição, Agostinho Ferreira ${ }^{126}$, Maria Ferreira e Ana da Encarnação. Por conseguinte as duas crianças ficaram com familiares próximos, nomeadamente tios e primos.

Fernão Lopes Milão parece ter acompanhado os restantes fugitivos, mas o resto da sua família ficou no Bairro Penitencial até que, na sexta-feira depois do Entrudo de 1611, o alcaide das Escolas Gerais deu o alarme. Guiomar Gomes e os seus filhos, Gomes Rodrigues, Ana de Milão, Isabel Henriques, Leonor Henriques; a sobrinha Beatriz Rodrigues; e a sua "cabra" Vitória Dias, moradores à Mouraria, tinham ido para a Flandres ${ }^{127}$. Deixaram para trás cinco anos de clausura sob alçada da Inquisição, tal como os seus bens e a vida do patriarca e dum seu criado.

Grande parte da família Milão reuniu-se em Hamburgo antes de 1617, juntando-se a Beatriz Henriques e Álvaro Dinis. Nesta cidade ficaram a mãe Guiomar Gomes, uma índia que com ela tinha sido presa (Vitória Dias); o Dr. Henrique Rodrigues e sua mulher ${ }^{128}$ (Leonor Henriques); Pêro de Palácios e esposa (Isabel Henriques); e Paulo de Milão. Mas outros optaram por se estabelecer em Amesterdão nomeadamente Gomes Rodrigues de Milão e Manuel Cardoso Milão ${ }^{129}$, provavelmente com as suas esposas e filhos. Pelo que se pôde apurar a tia Ana de Milão ${ }^{130}$ não conseguiu atrair à

${ }^{122}$ IANTT, $I L$, proc. 3335 e 3335-1.

${ }^{123}$ IANTT, $I L$, proc. 285.

${ }^{124}$ IANTT, $I L$, proc. 12347.

${ }^{125}$ IANTT, $I L$, proc. 9401.

${ }^{126}$ IANTT, $I L$, proc. 287.

${ }^{127}$ IANTT, $I L$, proc. 6671 , fl. 192.

${ }^{128}$ IANTT, $I L$, proc. 12493, fl. 11.

${ }^{129}$ IANTT, $I L$, proc. 12493, fl. 10. Na comunidade sefardita de Amesterdão Gomes adoptou o nome Daniel de Holanda, comerciava têxteis, jóias e açúcar para Hamburgo, foi um dos fundadores da comunidade judaica de Londres. Cf. Studia Rosenthaliana, vol. VI, $\mathrm{n}^{\mathrm{o}} 1$, Van Gorkun: University Library of Amsterdam, 1972, p. 120-121; BEN BRITH - Die Odyssee, p. 57.

${ }^{130}$ Ana de Milão foi presa (IL proc. 14409, 16420) e libertada pelo Perdão Geral de 1605, foi casada com Rodrigo de Andrade da família Rodrigues de Évora e Veiga. Ver DENUCÉ, Jean - Bijdrage tot de Geschiedenis van Oud Spaansch-Portugeesche Geslachten in Nederlanden. De Afkomst van Anna de Milan (c. 1548-1613) stammoeder 
Nação Portuguesa de Antuérpia os seus familiares, talvez porque o Judaísmo não fosse permitido na cidade do Escalda.

Após a fuga das Escolas Gerais, Fernão Lopes Milão esteve em Amesterdão onde, em 1612, continuou a desempenhar as suas actividades de mercador ${ }^{131}$ e parece ter adoptado o nome de Daniel Abensur. Contudo também é provável que o contratador de 55 anos registado por D. Diogo de Lima em Hamburgo por volta de 1630 com o nome de Fernão Lopes ou Jacob Lopes ${ }^{132}$ possa ser identificável com o Fernão Lopes Milão uma vez que a idade coincide.

No entanto, há algo que não faz sentido. O homem que escrevia em bocados de papel e aproveitava todas as oportunidades para se dedicar à escrita e estudo, mesmo nas condições mais adversas da vida, não deixou para a posteridade qualquer obra ${ }^{133}$ com o nome cristão ou judaico. Pelas fontes e bibliografia consultadas não se encontram vestígios da sua subsequente produção literária nas diversas comunidades sefarditas espalhadas pelo mundo. Todavia existe sempre a possibilidade de ter assumido um outro apelido judaico, que não o Abensur, uma outra identidade ou pseudónimo.

A modo de conclusão podemos dizer que nas malhas da Inquisição se perdeu uma vasta obra dum humanista que poderia ter iluminado as letras e contribuído para a difusão e afirmação da língua portuguesa. Mas também se perdeu um matemático e um filósofo cujos livros ficaram para sempre apagados da memória. Este estudo tentou reacender a luz sobre este importante homem do Renascimento Português.

van het geslacht Teixeira de Mattos, Antwerpsch Archivenblad, III, Baesrode-Dendermonde, Robert Bracke-van Geert, 1928.

${ }^{131}$ Studia Rosenthaliana, Vol. V, nº 2, 1971, p. 245.

${ }^{132}$ IANTT, $I L, L^{\circ} 226$, fl. 261 v; AZEVEDO, Pedro de - O Bocarro Francês e os judeus de Cochim e Hamburgo. Arquivo Histórico Português, vol. VIII, Lisboa, 1910, p. 19; ROTH, Cecil - Neue Kunde von der Marranen - Gemeinde in Hamburg. Zeitschrift für die Geschichte der Juden in Deutschland, Berlim: Philo Verlag, p. 234.

${ }^{133}$ Sobre literatura produzida por judeus sefarditas ver DEN BOER, Harm, La Literatura Sefardi de Amsterdam, Madrid: Universidad de Alcalá, 1995. 